\title{
Phenytoin intoxication during concurrent diazepam therapy
}

\author{
H O W A R D J. ROGERS, 1 R OBERT A. HASLA M, \\ J A M ES LONGSTRETH, AND PAULS. LIETMAN \\ From the Division of Clinical Pharmacology and JF Kennedy Institute, Johns Hopkins Hospital, \\ Baltimore, Maryland, USA
}

SUMMARY Phenytoin elimination is a saturable process obeying Michaelis-Menten kinetics. Plasma phenytoin levels are not related linearly to dose, and small changes in enzyme activity produced by concurrent drug therapy could alter plasma levels. Two cases of phenytoin intoxication associated with simultaneous administration of diazepam are reported. Intravenous phenytoin infusions were given and the apparent $K_{m}$ and $V_{\max }$ computed from the resulting plasma phenytoin levels. In one case ' $\mathrm{K}_{\mathrm{m}}$ ' and ' $\mathrm{V}_{\max }$ ' were $0.8 \mu \mathrm{mol} / 1$ and $1.3 \mu \mathrm{mol} / 1 / \mathrm{hour}$ respectively during concurrent diazepam administration, and $50.3 \mu \mathrm{mol} / 1$ and $4.4 \mu \mathrm{mol} / 1 / \mathrm{hour}$ after discontinuation of diazepam. In the second case phenytoin infusion with diazepam gave ' $\mathrm{K}_{\mathrm{m}}$ ' and ' $\mathrm{V}_{\max }$ ' values of $0.012 \mu \mathrm{mol} / 1$ and $0.95 \mu \mathrm{mol} / 1 /$ hour. Without diazepam these were $28.8 \mu \mathrm{mol} / 1$ and $0.92 \mu \mathrm{mol} / 1 /$ hour respectively.

Phenytoin possesses a relatively small therapeutic index, and toxicity is by no means uncommon during therapy making monitoring of plasma levels an important adjunct to clinical management (Dawson and Jamieson, 1971). This situation is further complicated by the non-linear relationship between dose and the resulting plasma concentration (Bochner et al., 1972). The apparent half-life of the drug increases as the plasma level rises, phenytoin elimination being described as dose-dependent. This type of elimination can be described as obeying Michaelis-Menten kinetics overall (Gerber and Wagner, 1972). It follows from these kinetic properties that the relationship of plasma levels to dose is non-linear, and that at higher plasma levels a small increase in dose produces a disproportionately large increase in plasma levels. The enzymatic parahydroxylation of phenytoin, or perhaps the subsequent glucuronide formation, may be the rate-limiting steps in phenytoin elimination, and small changes in enzyme activity, as might occur with the inhibition of one of these steps by concurrent drug therapy, could, therefore, produce marked changes in phenytoin elimination. Diazepam is sometimes used in con-

${ }^{1}$ Medical Research Council Travelling Fellow. Present address: Departments of Pharmacology and Clinical Pharmacology, Guy's Hospital Medical School, London, SE1 9RT, England.

Accepted 28 March 1977 junction with phenytoin and this drug also undergoes hydroxylation to oxazepam during its metabolism. We have observed two cases of clinically significant phenytoin intoxication occurring during concurrent administration of diazepam and we believe that this toxicity occurred by an interference with phenytoin elimination by diazepam.

\section{Case reports}

Patient 1 was a three year old male who became spastic and unresponsive after Haemophilus influenzae meningitis at the age of 7 months. At 15 months he was given $7.5 \mathrm{mg} / \mathrm{kg} / \mathrm{day}$ phenytoin for frequent myoclonic seizures which despite this treatment persisted, with worsening of the EEG. On this regime the steady state plasma levels were $28 \mu \mathrm{mol} / \mathrm{l}$. He was admitted to the JF Kennedy Institute for evaluation and the dose of phenytoin increased to $9 \mathrm{mg} / \mathrm{kg} /$ day which resulted in levels of $36 \mu \mathrm{mol} / 1$. Diazepam was added (for spasticity) in a dose of $0.3 \mathrm{mg} / \mathrm{kg} /$ day and increased by increments of $0.1 \mathrm{mg} / \mathrm{kg} /$ day at intervals of approximately five days to $0.6 \mathrm{mg} / \mathrm{kg} /$ day. Simultaneously the phenytoin dose was increased to $12.5 \mathrm{mg} / \mathrm{kg} /$ day. Fourteen days after the addition of diazepam and the increased dose of phenytoin the patient experienced phenytoin toxicity characterised by 
vomiting, pallor, and nystagmus; the phenytoin level was $116 \mu \mathrm{mol} / 1$. Phenytoin was withdrawn and after five days the plasma level was $50 \mu \mathrm{mol} / 1$ when the anticonvulsant was started again at a dosage of $11 \mathrm{mg} / \mathrm{kg} /$ day. Within eight days the plasma phenytoin level was $130 \mu \mathrm{mol} / 1$ and the child was clinically intoxicated. Diazepam had been given throughout this episode at $0.6 \mathrm{mg} / \mathrm{kg} /$ day. Both drugs were withdrawn and the phenytoin level fell to $34 \mu \mathrm{mol} / 1$ within four days. Phenytoin alone was then given at a dose of 12.5 $\mathrm{mg} / \mathrm{kg} /$ day and the patient rapidly attained steady state phenytoin levels fluctuating around a mean of $76 \mu \mathrm{mol} / 1$. After this a formal consultation was requested with the clinical pharmacology department and the studies detailed in the report were carried out.

Patient 2 was a 6 year old male who sustained severe brain damage after a traffic accident when craniotomy showed a contused brain. His postoperative course was complicated by generalised convulsions which were controlled by $5.5 \mathrm{mg} / \mathrm{kg}$ / day phenytoin. On discharge he was able to communicate in a nearly normal fashion and to walk independently, his main disability being a right sided intention tremor. He was under the care of a private paediatrician and no data on plasma levels of phenytoin are available preceding his admission. During his time at home, diazepam $(0.4 \mathrm{mg} / \mathrm{kg} /$ day) was added to the regimen to improve tremor, and after this his condition deteriorated over the course of eight weeks. He was admitted to the JF Kennedy Institute when examination showed a dysarthric, non-ambulatory boy with horizontal nystagmus, vertical gaze palsy, and a marked right sided intention tremor with bilateral ataxia. The plasma phenytoin level was $223.2 \mu \mathrm{mol} / 1$. Phenytoin, but not diazepam, was withdrawn, and the decreasing plasma levels were recorded and used to provide the data recorded in the Table as the oral data for this patient. When phenytoin was stopped there was marked improvement in socialisation, language, motor, and intellectual skills with disappearance of all cerebellar signs apart from minimal dysarthria. After our experience with patient 1 the intravenous studies detailed below were undertaken.

Neither patient showed abnormalities of renal or hepatic function, and haematological studies including serum folate levels were all normal.

\section{Methods}

Intravenous phenytoin administration The parents of both children gave informed consent for this study of phenytoin pharmacokinetics which was carried out according to a protocol approved by the Johns Hopkins Hospital joint committee on clinical investigations. The patients were given $15 \mathrm{mg} /$ $\mathrm{kg}$ phenytoin (Dilantin, Parke, Davis and Company) by intravenous infusion, using a Sage pump, over 30 minutes. Blood was drawn into heparinised capillary tubes from finger punctures at predetermined intervals. Intravenous phenytoin infusions were administered twice to each patient, the first during diazepam administration and the second two months after it was stopped.

Analysis of phenytoin plasma concentrations This was done by radio-immunoassay as described by Cook et al. (1973), using phenytoin antiserum kindly supplied by $\mathrm{Dr} \mathrm{H}$. Dix Christensen (Research Triangle Institute, Research Triangle Park, NC).

Pharmacokinetic analysis The observed data for the two patients were fitted to an integrated form of the Michaelis-Menten equation as given in the following equation using the NONLIN program (obtained from Dr C. M. Metzler of the Upjohn Company, Kalamazoo, Michigan).

$$
D-D_{0}+K_{m} \log _{e} \frac{D}{D_{o}}=V_{\max }\left(t-t_{o}\right)
$$

$D_{0}$ is phenytoin concentration at time $=t_{0}$ when the infusion was terminated, $V_{\max }$ is the maximum reaction velocity when the elimination is saturated, $\mathrm{K}_{\mathrm{m}}$ is the serum concentration giving $50 \%$ saturation, $D$ is phenytoin concentration, and $t$ is time elapsed from termination of the infusion.

Phenytoin elimination in vivo is unlikely to satisfy the strict criteria for the application of this equation but the system may approximate to Michaelis-Menten kinetics overall (Gerber and Wagner, 1972) and may be characterised by an apparent $K_{m}\left(' K_{m}\right.$ ') and an apparent $V_{\max }$ (' $V_{\max }$ ').

The parameters ' $\mathrm{K}_{\mathrm{m}}$ ', and ' $\mathrm{V}_{\max }$ ' were varied to obtain the best fit (by a least squares method) of the calculated curve to the observed data.

\section{Results}

The data for intravenous phenytoin infusion with and without concurrent diazepam administration in patient 1 are plotted on semilogarithmic coordinates in Fig. 1. The plots are curvilinear showing a continuously changing rate of elimination which decreases with the elevated plasma phenytoin level. Clearly the kinetics are not firstorder and imply capacity-limited drug elimination. The same data are plotted on linear coordinates in 
Fig. 2 for patient 1 , and similarly for patient 2 in Fig. 3.

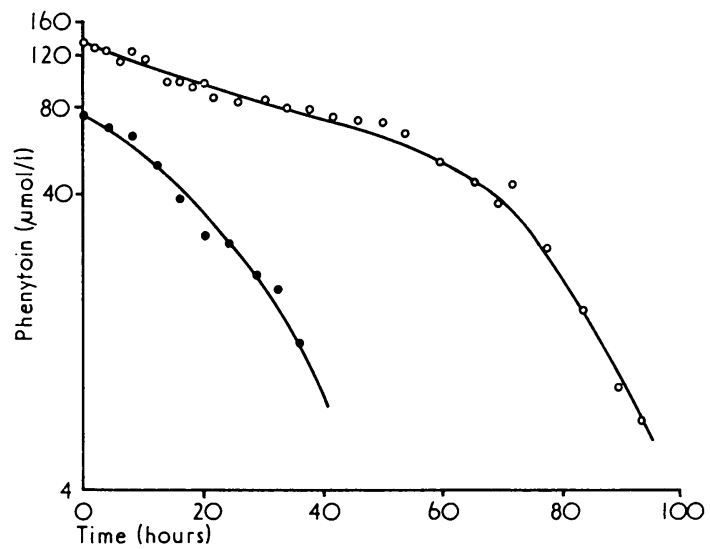

Fig. 1 Patient 1. Plasma phenytoin levels after infusion of $15 \mathrm{mg} / \mathrm{kg}$ phenytoin in the presence $(\mathrm{O})$ and absence (O) of $0.6 \mathrm{mg} / \mathrm{kg} /$ day diazepam orally.

(a)

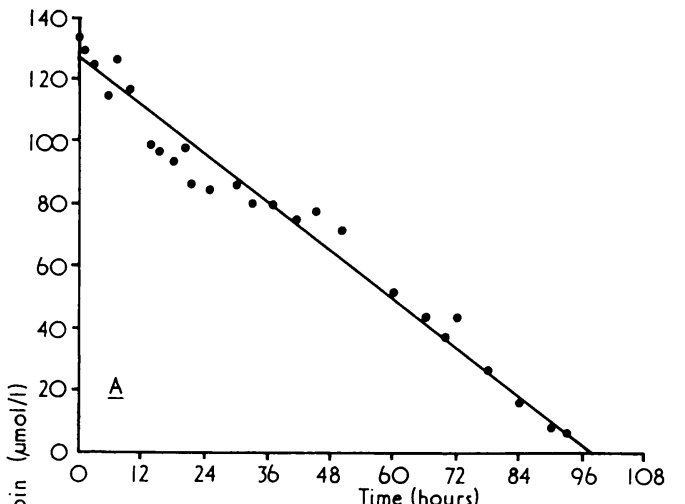

(b)

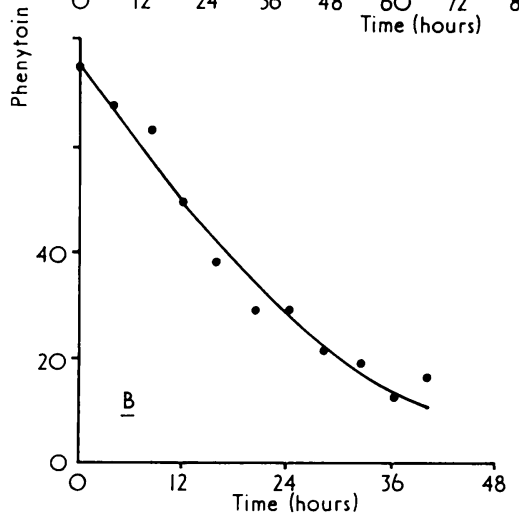

Fig. 2 Patient 1. Data from Figure 1 plotted on linear coordinates $(a)$ in presence of orally administered diazepam, and $(b)$ in absence of diazepam. Solid lines fitted from computer estimates of ' $K_{m}$ ' and ' $V_{\max }$ '. (a)

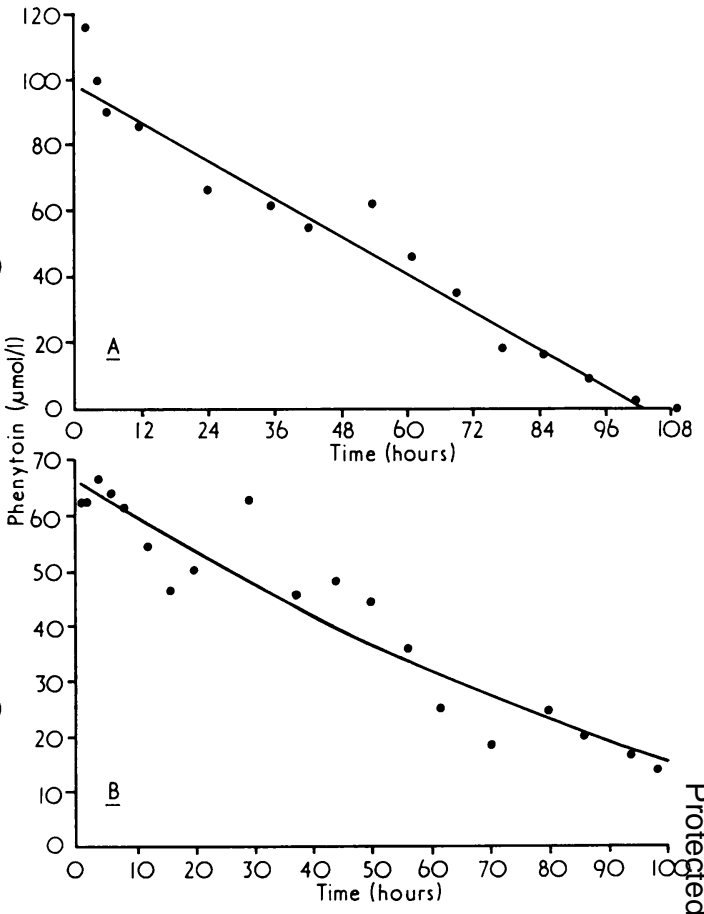

Fig. 3 Patient 2. Post-infusion data plotted on linear coordinates (a) $15 \mathrm{mg} / \mathrm{kg}$ phenytoin $i . v$. with 0.4 $\mathrm{mg} / \mathrm{kg} /$ day diazepam orally, and (b) $15 \mathrm{mg} / \mathrm{kg}$ phenytoin i.v. alone. Solid lines fitted from computer estimates of ' $K_{m}$ ' and $V_{\text {max }}$.

The computer estimates for ' $\mathrm{K}_{\mathrm{m}}$ ' and ' $\mathrm{V}_{\text {max }}$ ' are shown in the Table. Two estimates were available for these parameters in the presence of diazepam in both patients: one determined after discontinuation of oral phenytoin and one after the intravenous phenytoin infusion.

Table Computer estimates of apparent $K_{m}$ and apparent $V_{\max }$ for patients 1 and 2

\begin{tabular}{|c|c|c|c|c|}
\hline & Phenytoin & Diazepam & ' $K_{m}$ ' $(\mu \mathrm{mol} / \mathrm{l})$ & $\begin{array}{l}\text { 'V mar.' } \\
\text { ( } \mu \text { mol/l/hour })\end{array}$ \\
\hline \multirow[t]{3}{*}{ Patient 1} & i.v. infusion & .. & 0.8 & 1.3 \\
\hline & Oral & 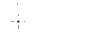 & $<4$ & 1.3 \\
\hline & i.v. infusion & - & 50.3 & 4.4 \\
\hline \multirow[t]{3}{*}{ Patient 2} & i.v. infusion & $\div$ & 0.012 & 0.95 \\
\hline & Oral & + & 0.012 & 0.75 \\
\hline & i.v. infusion & - & 28.8 & 0.92 \\
\hline
\end{tabular}

In the absence of diazepam, the calculated ' $\mathrm{K}_{\mathrm{m}}$ ' is in the same range as the plasma phenytoin concentration. Under such conditions the configuration and position of the elimination curve are largely determined by the value of ' $K_{m}$ ' and the good fit of the data to the computed line suggests 
that this calculated ' $\mathrm{K}_{\mathrm{m}}$ ' value has relatively narrow limits of uncertainty. Furthermore, for a given ' $\mathrm{K}_{\mathrm{m}}$ ' the allowable range of values of ' $V_{\max }$ ' is quite limited so that reasonable certainty can be given to the actual values of both of these parameters when diazepam is absent. We would not wish to claim that these values represent a unique solution to the data. In itself, the adoption of Michaelis-Menten kinetics for the description of phenytoin pharmacokinetics is an oversimplification of the situation. The statistics generated by the program to characterise the uncertainty of the estimated constants probably generate spurious confidence in their accuracy since the amount of data available is relatively sparse. Variation of the magnitude of the constants alters the goodness of fit of the computed line to the experimental points as evidenced by an increase in the residual sum of squares and a worse visual fit of the data.

When diazepam is present the computed ' $\mathrm{K}_{\mathrm{m}}$ ' values are much less than the experimentally determined plasma phenytoin concentrations. Using the Michaelis-Menten equation, an approximation of zero order kinetics occurs if the value of $\mathrm{K}_{\mathrm{m}}$ is at least tenfold less than the substrate concentration under consideration. The actual values of ' $\mathrm{K}$ ' calculated for this situation and given in the Table contain a large amount of uncertainty relative to their small magnitude: it is certain, however, that ' $\mathrm{K}_{\mathrm{m}}$ ' is negligible compared to the drug concentration. On the other hand, the calculated value of ' $V_{\max }$ ' has a relatively narrow range of uncertainty because it is the only parameter capable of providing a continuous curve that approximates the observed data.

\section{Discussion}

The toxicity observed in these two patients includes the clinical features of nystagmus, ataxia, dysarthria, lethargy, and inability to concentrate which have been shown to be related to plasma phenytoin levels (Kutt et al., 1964). As in previously reported cases, the toxicity was reversible with reduction of the plasma phenytoin concentration.

Interaction between benzodiazepines and phenytoin is not well-documented. Chlordiazepoxide has been cited as a cause of elevated phenytoin plasma levels (Kutt and McDowell, 1968). Kariks et al. (1971) state that in a group of institutionalised epileptic patients treated with phenytoin those receiving diazepam in addition may have higher plasma phenytoin levels. In a report by Shuttleworth et al. (1974) concerned with choreoathetosis and phenytoin intoxication, one of the three cases discussed (case 2) developed choreoathetosis associated with raised plasma phenytoin levels while being treated with diazepam. Details were not given on the temporal relationship of toxicity to diazepam administration but toxicity did not reappear when this patient was restarted on phenytoin alone. This patient's illness was attributed to voluntary overdosage but might also be explained by a drug interaction. The best documented evidence of an interaction between diazepam and phenytoin comes from the study of Vajda et al. (1971) in which phenytoin was given to evaluate its effect as an anti-arrhythmic agent after myocardial infarction. Some patients also received chlordiazepoxide or diazepam, and in all five cases where phenytoin plasma levels were available before and after benzodiazepine administration, these levels were markedly increased after benzodiazepine therapy. Furthermore, in a large group of patients it was found that mean plasma phenytoin levels were significantly higher if benzodiazepines were simultaneously given with phenytoin. Houghton and Richens (1974), on the other hand, found a small but significant fall in serum phenytoin levels when benzodiazepines were given. This was associated with a reduced phenytoin half-life and a change in the ratio of 5-p-hydroxyphenyl-5-phenylhydantoin to phenytoin in favour of the metabolite. They suggested that benzodiazepines act as weak inducing agents in this situation.

The mechanism for the apparent saturation of the system for phenytoin elimination seen in our cases is unknown but saturation of the enzyme catalysing phenytoin hydroxylation is a possibility. Studies on phenytoin metabolism by rat liver microsomes in vitro by Kutt and Verebely (1970) showed the drug to be metabolised by an enzymic process obeying Michaelis-Menten kinetics, the rate-limiting step being parahydroxylation to 5$p$-hydroxyphenyl-5-phenylhydantoin. Measurement of the apparent $K_{m}$ for this process gave a mean value of $37.3 \mu \mathrm{mol} / 1$. In our patients, in the absence of diazepam, the ' $\mathrm{K}_{\mathrm{m}}$ ' was $50.3 \mu \mathrm{mol} / 1$ in patient 1 and $28.8 \mu \mathrm{mol} / 1$ in patient 2 . Although the correlation of an apparent $K_{m}$ estimated using isolated organelles with a ' $K_{m}$ ' determined from patient data must be viewed with caution, these values are of the same order of magnitude. The parameters calculated for our patients may be compared with a ' $\mathrm{K}_{\mathrm{m}}$ ' of $26.8 \mu \mathrm{mol} / 1$ and a ' $\mathrm{V}_{\max }$ ' of $1 \mu \mathrm{mol} / 1 /$ hour determined by Gerber and Wagner (1972) for a single subject and with the mean values of a ' $\mathrm{K}_{\mathrm{m}}$ ' of $15.1 \mu \mathrm{mol} / 1$ and ' $\mathrm{V}_{\text {max }}$ ' $1.36 \mu \mathrm{mol} / \mathrm{l} / \mathrm{hour}$ determined by Mawer et al. (1974) from 15 patients. 
Kutt and Verebely (1970) found that diazepam inhibited phenytoin metabolism by rat liver microsomes in vitro. With $10^{-3} \mathrm{M}$ diazepam $91 \%$ inhibition occurred, and $32 \%$ inhibition with $10^{-4} \mathrm{M}$, but the type of inhibition was undetermined. During diazepam therapy the plateau plasma levels are of the order of $0.7 \mu \mathrm{mol} / 1$ (Kaplan et al. 1973) which is clearly much lower than the level required to produce inhibition in the in vitro microsomal system. Metabolism of diazepam produces an accumulation of desmethyldiazepam which might also inhibit phenytoin metabolism. Mouse liver probably corresponds to a part of the deep compartment of the pharmacokinetic model describing diazepam kinetics and rapidly takes up diazepam, releasing the drug slowly (Van der Kleijn et al., 1971). Thus diazepam plasma levels per se, may not indicate the true drug concentration at the site of phenytoin metabolism. It is also possible that other diazepam metabolites could alter phenytoin metabolism. Because both phenytoin and diazepam are metabolised by hydroxylation it is tempting to postulate a competitive interaction, but some inhibitory effect on phenytoin glucuronide formation or elimination cannot be ruled out. Our data, being based on indirect estimates of the reaction parameters of a complex system, are unable to elucidate this question, and it is not possible to offer an interpretation of the mechanistic significance of the changes that we observed in the ' $\mathrm{K}_{\mathrm{m}}$ ' and ' $\mathrm{V}_{\max }$ ' in these two patients. Our data indicate, however, that the change in drug disposition after diazepam administration cannot be explained completely by a change in phenytoin metabolism. In both patients the intravenous administration of the same dose of phenytoin in the presence and absence of diazepam resulted in higher initial post-infusion plasma phenytoin levels (at $t_{0}$ ) in the former case (Figs. 2 and 3). If phenytoin metabolism alone were affected by diazepam a lengthening of the zero order phase would be expected: this suggests that other variables-for example, an alteration in the apparent volume of distribution for phenytoinmay be at work.

The data from case 2 , even in the absence of diazepam, suggest that this patient had a slow rate of phenytoin elimination (Kutt, 1971). This may have put him at special risk for phenytoin toxicity when diazepam was added to his antiepileptic drug therapy. That prolonged elevations of plasma phenytoin level may occur is illustrated by this patient whose phenytoin levels remained raised for several days after withdrawal of oral phenytoin during which time he remained toxic. The descending limb of this curve provided the second estimate for ' $\mathrm{K}_{\mathrm{m}}$ ' and ' $\mathrm{V}_{\max }$ ' in the Table.

We conclude that the interaction between diazepam and phenytoin is of clinical significance although its prevalence has yet to be determined. The report of Vajda et al. (1971) suggests that it could be relatively common, although the work of Houghton and Richens (1974) indicates that not all patients may respond in the same way to this drug combination. Probably a similar interaction may apply to other benzodiazepines, and with increasing use of these compounds as adjuncts in the control of epilepsy this interaction may be of increasing importance in the future.

The authors wish to thank Ms Meg Sonneborn for excellent technical assistance.

\section{References}

Bochner, F., Hooper, W. D., Tyrer, J. H., and Eadie, M. D. (1972). Effect of dosage increments on blood phenytoin concentrations. Journal of Neurology, Neurosurgery, and Psychiatry, 35, 873-876.

Cook, C. E., Kepler, J. A., and Christensen, H. D. (1973). Antiserum to diphenylhydantoin: prepara-응

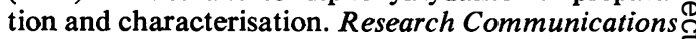
in Chemical Pathology and Pharmacology, 3, 455466.

Dawson, K. P., and Jamieson, A. (1971). Value of blood diphenylhydantoin estimation in the management of childhood epilepsy. Archives of Disease in Childhood, 46, 386-388.

Gerber, N., and Wagner, J. G. (1972). Explanation? of dose-dependent decline of diphenylhydantoin plasma levels by fitting to the integrated form of the Michaelis-Menten equation. Research Communications in Chemical Pathology and Pharmacology, 3, 455-466.

Houghton, G. W., and Richens, A. (1974). The effect of benzodiazepines and pheneturide on phenytoin metabolism. British Journal of Clinical Pharmacology, 1, 344-345 P.

Kaplan, S. A., Jack, M. L., Alexander, K., and Weinfeld, R. E. (1973). Pharmacokinetic profile of diazepam in man following single intravenous and oral and chronic oral administration. Journal of Pharmaceutical Sciences, 62, 1789-1796.

Kariks, J., Berry, S. W., and Wood, D. (1971). Serum folic acid and phenytoin levels in permanently hospitalised epileptic patients receiving anticonvulsant drug therapy. Medical Journal of Australia, 2, 369-371.

Kutt, H. (1971). Biochemical and genetic factors regulating Dilantin metabolism in man. Annals of the New York Academy of Sciences, 179, 704-722.

Kutt, H., Winters, W., Kokenge, R., and McDowell, F. (1964). Diphenylhydantoin metabolism, blood levels and toxicity. Archives of Neurology (Chicago), 11, 642-648.

Kutt, H., and McDowell, F. (1968). Management of 
epilepsy with diphenylhydantoin sodium. Journal of the American Medical Association, 203, 969-972.

Kutt, H., and Verebely, K. (1970). Metabolism of diphenylhydantoin by rat liver microsomes. I Characteristics of the reaction. Biochemical Pharmacology, 19, 675-686.

Mawer, G. E., Mullen, P. W., Rodgers, M., Robins, A. J., and Lucas, S. B. (1974). Phenytoin dose adjustment in epileptic patients. British Journal of Clinical Pharmacology, 1, 163-168.

Shuttleworth, E., Wise, G., and Paulson, G. (1974).
Choreoathetosis and diphenylhydantoin intoxication Journal of the American Medical Association, 230, 1170-1171.

Vajda, F. J. E., Prineas, R. J., and Lovell, R. R. H. (1971). Interaction between phenytoin and the benzodiazepines. British Medical Journal, 1, 346.

Van der Kleijn, E., van Rossum, J. M., Muskens, E. T. J. N., and Rijntjes, N. V. (1971). Pharmacokinetics of diazepam in dogs, mice and humans. Acta Pharmacologica et Toxicologica, 29, Supplement 3, 109-127. 